\title{
Intensive care, right ventricular support and lung transplantation in patients with pulmonary hypertension
}

\author{
Marius M. Hoeper ${ }^{1}$, Raymond L. Benza², Paul Corris ${ }^{3}$, Marc de Perrot ${ }^{4}$, \\ Elie Fadel ${ }^{5}$, Anne M. Keogh ${ }^{6,7}$, Christian Kühn ${ }^{8}$, Laurent Savale $\mathbb{1}^{9,10,11}$ and \\ Walter Klepetko ${ }^{12}$
}

Number 7 in the series

"Proceedings of the 6th World Symposium on Pulmonary Hypertension"

Edited by N. Galiè, V.V. McLaughlin, L.J. Rubin and G. Simonneau

\begin{abstract}
Affiliations: ${ }^{1}$ Dept of Respiratory Medicine, Hannover Medical School and Member of the German Center for Lung Research (DZL), Hannover, Germany. ${ }^{2}$ The Cardiovascular Institute, Allegheny General Hospital, Pittsburgh, PA, USA. ${ }^{3}$ Institute of Cellular Medicine, Newcastle University and Newcastle Hospitals NHS Foundation Trust, Newcastle upon Tyne, UK. ${ }^{4}$ Division of Thoracic Surgery, Toronto General Hospital, University of Toronto, Toronto, ON, Canada. ${ }^{5}$ Dept of Thoracic and Vascular Surgery and Heart-Lung Transplantation, Hôpital Marie Lannelongue and Université Paris-Sud, Paris, France. ${ }^{6}$ Heart Transplant Unit, St Vincent's Public Hospital, Darlinghurst, Australia. ${ }^{7}$ University of New South Wales, Sydney, Australia. ${ }^{8}$ Dept of Cardiothoracic, Vascular and Transplantation Surgery, Hannover Medical School and Member of the German Center for Lung Research (DZL), Hannover, Germany. ${ }^{9}$ Université Paris-Sud, Faculté de Médecine, Université Paris-Saclay, Le Kremlin-Bicêtre, France. ${ }^{10} \mathrm{AP}-\mathrm{HP}$, Service de Pneumologie, Département Hospitalo-Universitaire (DHU) Thorax Innovation (TORINO), Hôpital Bicêtre, Le Kremlin-Bicêtre, France. ${ }^{11}$ INSERM UMR_S 999, Hôpital Marie Lannelongue, Le Plessis-Robinson, France. ${ }^{12}$ Dept of Thoracic Surgery, Medical University of Vienna, Vienna, Austria.
\end{abstract}

Correspondence: Marius M. Hoeper, Dept of Respiratory Medicine, Hannover Medical School, Carl-NeubergStrasse 1, 30625 Hannover, Germany. E-mail: hoeper.mariusamh-hannover.de

@ERSpublications

State of the art and research perspectives on the ICU management of patients with pulmonary hypertension and right heart failure, the timing of transplant referral, and the use of extracorporeal life support http://ow.ly/pISA30mfQk4

Cite this article as: Hoeper MM, Benza RL, Corris P, et al. Intensive care, right ventricular support and lung transplantation in patients with pulmonary hypertension. Eur Respir J 2019; 53: 1801906 [https://doi. org/10.1183/13993003.01906-2018].

ABSTRACT Intensive care of patients with pulmonary hypertension $(\mathrm{PH})$ and right-sided heart failure includes treatment of factors causing or contributing to heart failure, careful fluid management, and strategies to reduce ventricular afterload and improve cardiac function. Extracorporeal membrane oxygenation (ECMO) should be considered in distinct situations, especially in candidates for lung transplantation (bridge to transplant) or, occasionally, in patients with a reversible cause of right-sided heart failure (bridge to recovery). ECMO should not be used in patients with end-stage disease without a realistic chance for recovery or for transplantation. For patients with refractory disease, lung transplantation remains an important treatment option. Patients should be referred to a transplant centre when they remain in an intermediate- or high-risk category despite receiving optimised pulmonary arterial hypertension therapy. Meticulous peri-operative management including the intra-operative and postoperative use of ECMO effectively prevents graft failure. In experienced centres, the 1-year survival rates after lung transplantation for $\mathrm{PH}$ now exceed $90 \%$. 


\section{Introduction}

The present article addresses the management of patients with advanced pulmonary hypertension $(\mathrm{PH})$ or pulmonary arterial hypertension (PAH) and right-sided heart failure, focusing on intensive care, use of extracorporeal life support (ECLS) and lung transplantation. Other causes of right-sided heart failure as seen for instance in patients with acute pulmonary embolism, right ventricular infarction or right-sided heart failure secondary to left-sided heart failure will not be discussed here.

The following definitions of right-sided heart failure will be used:

1) Right-sided heart failure is characterised by low cardiac output and/or elevated right-sided filling pressures due to systolic and/or diastolic right ventricular dysfunction.

2) Right-sided heart failure is severe if it leads to secondary dysfunction of other organs and tissues, in particular liver, kidneys and gut.

This article addresses topics where robust data from large clinical trials are not available. Hence, most of the statements and recommendations are based on clinical experience and expert consensus rather than scientific evidence.

\section{Pathophysiology of right-sided heart failure}

The pathophysiology of right-sided heart failure has been described in depth elsewhere [1-3]. Here, only a couple of points will be highlighted that are considered of importance for treatment considerations.

Like left-sided heart failure, right-sided heart failure may present as isolated systolic heart failure or isolated diastolic heart failure; however, combined forms are frequently encountered in patients requiring treatment on the intensive care unit (ICU). Systolic right-sided heart failure results in left ventricular underfilling and low cardiac output, which impairs tissue perfusion and oxygenation. Diastolic right-sided heart failure results in elevated systemic venous pressure with detrimental consequences for tissue perfusion and oxygenation as well.

With increasing afterload, the right ventricle remodels, i.e. hypertrophies and eventually dilates, developing a spherical shape accompanied by increased right ventricular wall stress, impaired myocardial contractility and progressive tricuspid regurgitation, which further reduces effective cardiac output. Ventricular interdependence results in impaired left ventricular filling and function.

Severe right-sided heart failure affects all organ systems; in the ICU setting, the consequences for the liver, kidneys and gut are often most relevant. Several lines of evidence suggest that elevated venous pressures with chronic congestion are particularly damaging to these organs [4-9]. Malperfusion and congestion alter bowel wall permeability, and may cause translocation of bacteria and endotoxins from the bowel into the circulation resulting in a systemic inflammatory response or sepsis $[4,10,11]$, which are common contributors to death in patients with right-sided heart failure [12].

\section{Symptoms and signs of right-sided heart failure}

Symptoms and signs of low cardiac output failure can be subtle. Tachycardia is often present, while systemic hypotension usually develops only at advanced stages. The skin may have a pale appearance; cyanosis may be present but is not obligate. Patients frequently complain about fatigue and appear tired. Agitation may be present as well and may signal imminent death. The clinical signs of right-sided backward failure such as prominent and pulsating jugular veins, ascites, and oedema are usually obvious.

\section{Principles of ICU monitoring of patients with right-sided heart failure}

ICU monitoring of patients with $\mathrm{PH} / \mathrm{PAH}$ and right-sided heart failure should focus on cardiac function and the function of other organs (table 1).

In patients requiring ICU treatment, monitoring of cardiac function is essential. Right heart catheterisation, preferably with continuous cardiac output measurement, is not always necessary, but should be considered in severe and complex cases. Other tools to measure cardiac output should be considered as well.

Insertion of a central venous line is considered mandatory in patients requiring ICU treatment for right-sided heart failure. Central venous pressure measurement, which has been abandoned in most ICU patients due to poor correlation with fluid status, is pivotal in patients with right ventricular failure to determine right-sided filling pressures, keeping in mind the detrimental effects of elevated filling pressures (see earlier). In addition, central venous oxygen saturation $\left(\mathrm{S} \mathrm{cvO}_{2}\right)$ measurements are important to determine tissue oxygenation as $\mathrm{ScrO}_{2}$ correlates with cardiac output [13]. 
TABLE 1 Intensive care unit (ICU) monitoring of patients with right-sided heart failure

Tools

Information provided

Basic ICU monitoring

Heart rate and rhythm

Blood pressure (non-invasive or invasive)

Body temperature

Peripheral oxygen saturation or arterial blood gases

Urine output, changes in body weight

Central venous catheter

Central venous pressure

Central venous oxygen saturation

Laboratory values

Cardiac biomarkers (N-terminal pro-brain natriuretic peptide/brain natriuretic peptide, troponin) Electrolytes and renal function (estimated glomerular filtration rate, blood urea nitrogen, uric acid) Liver function (aminotransferases, bilirubin)

Inflammation/infection (C-reactive protein, procalcitonin)

Tissue damage or hypoxia (blood gases, lactate)

Echocardiography

Right and left ventricle function, valve function, pericardial effusion

Rule out other conditions mimicking right ventricular failure, such as pericardial tamponade

Right heart catheterisation

Comprehensive haemodynamic assessment

(facultative)

To be considered in severe or complex situations

Recommendations for ICU monitoring of patients with $\mathrm{PH}$ and severe right-sided heart failure

- ICU monitoring of patients with severe right-sided heart failure should include regular measurements of central venous pressure and $\mathrm{S}_{\mathrm{cvO}}$.

- Key warning signs of imminent death in patients with right-sided heart failure are a decline in $\mathrm{ScvO}_{2}$ accompanied by an increase in lactate and a decline in urine output.

- The use of right heart catheterisation or other devices to monitor haemodynamics and cardiac output should be considered in patients with severe right-sided heart failure and in complex situations.

\section{ICU treatment of severe right-sided heart failure}

Patients with severe right-sided heart failure require comprehensive care including treatment of factors causing or contributing to heart failure, fluid management and strategies to improve cardiac function (figure 1). If possible, such patients should be treated at expert centres capable of providing all treatment options, i.e. medical therapy, ECLS and lung transplantation. Interhospital transfer must be considered on an individual basis. Some centres provide mobile units facilitating interhospital transfer with ECLS [14].

Treatable precipitants of right-sided heart failure include infection, anaemia, thyroid dysfunction, pulmonary embolism, arrhythmia or non-adherence to prescribed medications. Supraventricular tachyarrhythmias, especially atrial flutter and atrial fibrillation, are common causes of right-sided heart failure in patients with severe $\mathrm{PH}$ [15] and rapid restoration of sinus rhythm should be attempted in such cases. Infection is another important contributor to death in patients with right-sided heart failure. If the source of infection is not obvious, broad-spectrum antibiotics should be considered bearing in mind that translocation from the bowel is a frequent cause of systemic inflammation and sepsis in patients with right-sided heart failure $[10,11]$.

Supplementary oxygen should be administered as needed to maintain peripheral oxygen saturations $>90 \%$. Hypercapnic patients may benefit from non-invasive ventilation [16], although caution is necessary as even non-invasive ventilation may further impair right ventricular function [17]. Whenever possible, intubation and invasive mechanical ventilation should be avoided in patients with severe right heart failure, as the induction of general anaesthesia together with a further increase in right ventricular afterload carries a high risk of death in these patients. If intubation is unavoidable, maintaining a stable blood pressure is of key importance.

Fluid management is often critical in patients with right-sided heart failure. It is a common reflex among intensivists to administer fluids to patients with hypotension or shock. Only rarely are patients with right-sided heart failure fluid-depleted as well. Most of these patients have markedly elevated right-sided filling pressures and a low cardiac output. In these patients, fluid administration may further increase right-sided filling pressures and chamber dimensions, thereby aggravating the shift of the interventricular septum to the left and increasing tricuspid regurgitation [18], all resulting in further deterioration of left 


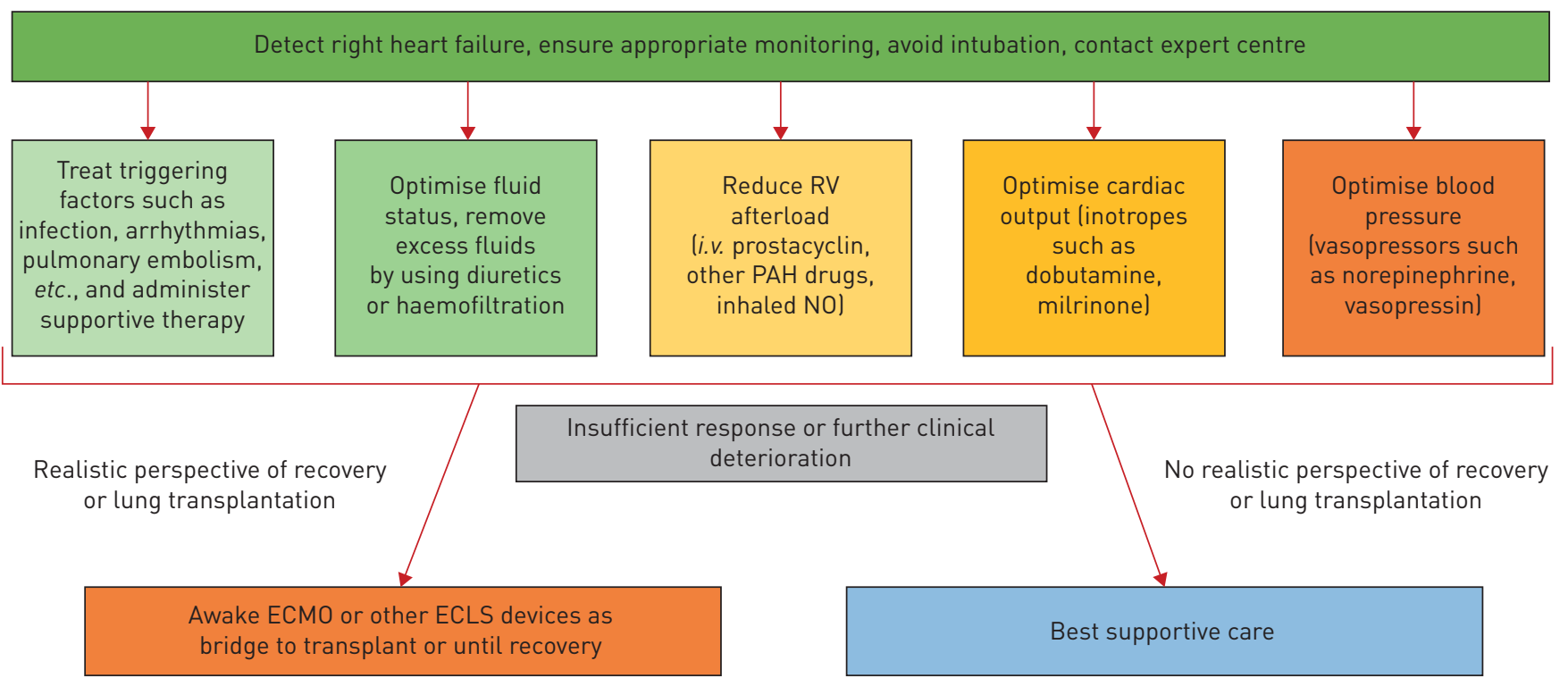

FIGURE 1 Therapeutic approach to patients with severe right-sided heart failure. RV: right ventricular; PAH: pulmonary arterial hypertension; NO: nitric oxide; ECMO: extracorporeal membrane oxygenation; ECLS: extracorporeal lung support. Reproduced and modified from [80] with permission.

ventricular filling and function, as illustrated in figure 2. In such patients, a negative fluid balance should be sought by using i.v. loop diuretics or even haemofiltration [19].

To reduce right ventricular afterload, all drugs approved for PAH may be considered in patients presenting with severe right-sided heart failure. Intravenous prostacyclin analogues (PCAs) are usually preferred because of their efficacy and a rapid onset of action. Initial triple combination therapy consisting of i.v. epoprostenol, oral phosphodiesterase type 5 inhibitors and endothelin receptor antagonists in patients with newly diagnosed $\mathrm{PAH}$ and right-sided heart failure has been reported with excellent short-term and mid-term results [20].

Patients with low cardiac output may initially require the use of inotropes, with dobutamine and milrinone being the most widely used agents in this setting. In animal models of right-sided heart failure, levosimendan appears more effective than dobutamine [21, 22], but reliable clinical data are lacking. Patients with a low systemic vascular resistance may need additional vasopressor treatment. Norepinephrine and vasopressin are the preferred agents. Vasopressin may be advantageous as it has pulmonary vasodilator effects $[23,24]$, but the clinical relevance of this property is unknown (table 2).

\section{Recommendations for ICU treatment of patients with severe right-sided heart failure}

- Patients with PAH or other forms of severe PH with right-sided heart failure requiring ICU therapy should be treated at expert centres capable of providing all treatment options, i.e. medical therapy, ECLS and advanced treatment including lung transplantation, if possible.

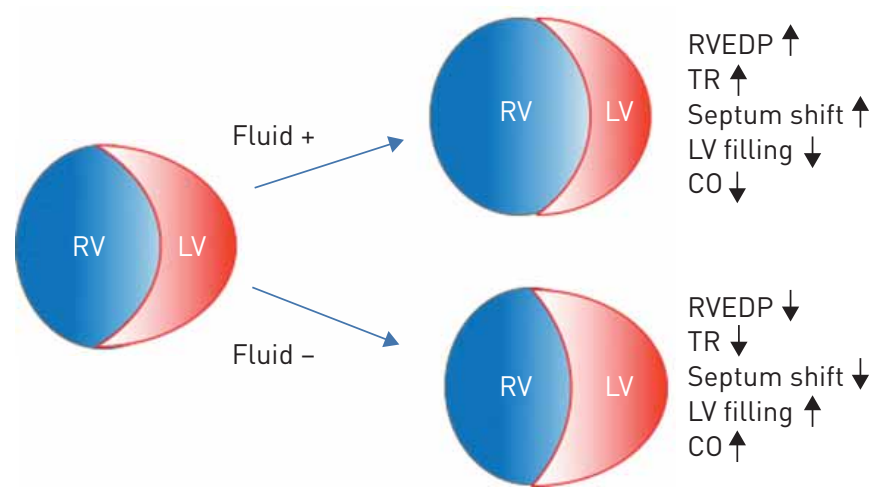

FIGURE 2 Effects on volume changes on cardiac function in right-sided heart failure. RV: right ventricle; LV: left ventricle; RVEDP: right ventricular end-diastolic pressure; TR: tricuspid regurgitation; CO: cardiac output. Reproduced and modified from [80] with permission. 


\begin{tabular}{|c|c|c|c|c|c|c|}
\hline Drug & $\begin{array}{c}\text { Cardiac } \\
\text { output }\end{array}$ & PVR & SVR & $\begin{array}{l}\text { Tachycardia/ } \\
\text { arrhythmia }\end{array}$ & $\begin{array}{l}\text { Pre-clinical } \\
\text { studies }\end{array}$ & $\begin{array}{l}\text { Clinical studies/ } \\
\text { experience }\end{array}$ \\
\hline \multicolumn{7}{|l|}{ Inotropes } \\
\hline \multicolumn{7}{|l|}{ Dobutamine } \\
\hline$<5 \mu \mathrm{g} \cdot \mathrm{kg}^{-1} \cdot \mathrm{min}^{-1}$ & $\uparrow$ & $\searrow$ & $\rightarrow$ or $\searrow$ & ++ & +++ & Large clinical experience, \\
\hline $5-15 \mu \mathrm{g} \cdot \mathrm{kg}^{-1} \cdot \mathrm{min}^{-1}$ & $\uparrow \uparrow$ & $\rightarrow$ & $\searrow$ & +++ & & haemodynamic studies \\
\hline \multicolumn{7}{|l|}{ Dopamine } \\
\hline $2.5-5 \mu \mathrm{g} \cdot \mathrm{kg}^{-1} \cdot \min ^{-1}$ & $\uparrow$ & $?$ & $\uparrow \uparrow$ & & $+/-$ & $\uparrow$ Renal blood flow \\
\hline$>5 \mu \mathrm{g} \cdot \mathrm{kg}^{-1} \cdot \mathrm{min}^{-1}$ & $\uparrow$ & $\uparrow$ & & +++ & & \\
\hline Milrinone & $\uparrow \uparrow$ & $\searrow$ & $\searrow \searrow$ & +++ & ++ & Group $2 \mathrm{PH}$ case reports in $\mathrm{PAH}$ \\
\hline Levosimendan & $\uparrow \uparrow$ & $\searrow$ & $\searrow \searrow$ & + & ++ & Group $2 \mathrm{PH}$ case reports in $\mathrm{PAH}$ \\
\hline Epinephrine & $\uparrow \uparrow$ & $\searrow$ & $\uparrow \uparrow$ & +++ & & $\begin{array}{c}\text { Effective, but risk of myocardial } \\
\text { necrosis and lactic acidosis }\end{array}$ \\
\hline \multicolumn{7}{|l|}{ Vasopressors } \\
\hline Norepinephrine & $\uparrow$ & $\rightarrow$ or $\uparrow$ & $\uparrow \uparrow$ & ++ & ++ & Large clinical experience \\
\hline Vasopressin (low doses) & $\rightarrow$ or $\uparrow$ & $\searrow$ & $\uparrow \uparrow$ & +++ & ++ & Limited clinical data in $\mathrm{PAH}$ \\
\hline
\end{tabular}

PVR: pulmonary vascular resistance; SVR: systemic vascular resistance; PH: pulmonary hypertension; PAH: pulmonary arterial hypertension.

- Interhospital transfer should be considered on an individual basis. Some centres provide mobile units facilitating interhospital transfer with ECLS.

- ICU treatment of patients with right-sided heart failure should include treatment of underlying causes and comorbidities, supportive measures, meticulous fluid management, reduction of right ventricular afterload with drugs approved for PAH, and an individualised use of inotropes and vasopressors.

\section{Mechanical support of the right heart}

In patients with right-sided heart failure refractory to treatment, mechanical support should be considered in certain situations, i.e. in candidates for lung transplantation (bridge to transplant) and, occasionally, in patients with a treatable cause of right-sided heart failure or in hitherto treatment-naive patients (bridge to recovery).

\section{Technical principles and features of mechanical right ventricular support}

There are various devices and device configurations to support the right ventricle, and the list is constantly growing $[25,26]$. At present, the most widely used techniques are peripheral veno-arterial extracorporeal membrane oxygenation (ECMO) and pumpless membrane oxygenators inserted between the pulmonary artery and the pulmonary veins or left atrium (PA-LA).

Peripheral ECMO support is usually established via the femoral vessels but upper body approaches have been used as well, the latter mostly to enable ambulation, which is not possible with lower body cannulation. The veno-arterial configuration ensures rapid and effective unloading of the right ventricle [27]. With residual pulmonary blood flow, an ECMO blood flow of $2.5-4 \mathrm{~L} \cdot \mathrm{min}^{-1}$ is usually adequate to maintain sufficient perfusion of the entire organism, while effectively unloading the right ventricle and avoiding an unnecessary increase in left ventricular afterload. Still, this configuration is characterised by opposing blood flows in the aorta, one coming from the left ventricle, the other from the ECMO system. The area where these two blood flows meet is called the ECMO watershed, which is clinically relevant mostly for differential oxygenation [28]. In patients with femoral veno-arterial ECMO support, the lower body is supplied by blood originating from the ECMO and the upper body by blood coming from the heart. The location of the watershed is variable, and depends on the respective pressures and flows in the two circuits. While lower body oxygenation is safely maintained by ECMO, upper body oxygenation can be impaired when the blood coming from the left heart carries a low oxygen content. This affects predominantly the brain and the heart itself. While brain oxygenation can be indirectly monitored by right forearm oxygenation, it is usually not possible to measure the oxygen content in the aortic bulb and the coronary arteries. Hence, monitoring of cardiac function by regular troponin measurements and echocardiography is mandatory.

With the PA-LA approach, a membrane oxygenator is placed between the pulmonary artery and the left atrium. In patients with $\mathrm{PH}$, a pump is usually not required, at least when low-resistance membranes are being used $[29,30]$. PA-LA insertion is more complex than ECMO support as it requires surgery via 
sternotomy or antero-lateral thoracotomy. In addition, patients with advanced right-sided heart failure often need temporary ECMO support prior to anaesthesia. The main advantages of the PA-LA approach are that 1) ambulation is feasible, 2) oxygen-enriched blood enters the left ventricle and thereby the entire systemic circulation, and 3) the pre-load of the left ventricle is increased, which helps "priming" for the haemodynamic situation after transplantation (see later).

\section{Right ventricular assist devices}

There are sporadic reports on isolated right ventricular assist device (RVAD) support in PAH [31]. However, successful long-term use of RVADs in patients with PAH has not yet been reported. The role of this intervention is limited given the pathophysiology of $\mathrm{PAH}$, which may include aggravation of pulmonary vascular remodelling, risk of pulmonary bleeding and induction of pulmonary oedema in patients with left ventricular diastolic dysfunction [32-34]. For these reasons, isolated RVAD support should be used with utmost care or not at all in these patients. Smaller-sized devices with good ability to control the pump flow in the pulmonary circulation may open new options in the future [35].

\section{Indications for mechanical support of the right ventricle}

The only established option for the use of ECLS in patients with $\mathrm{PH}$ and right-sided heart failure is bridge to transplantation (table 3) $[36,37]$. Hence, ECLS should be considered 1) if conventional treatment strategies fail in patients who 2) have already been fully evaluated for lung transplantation, who 3) have a realistic chance of receiving a donor organ in a reasonable time frame and who 4) can still be expected to have a good outcome after transplantation [26]. If possible, ECMO should preferably be used in awake, non-intubated and spontaneously breathing patients, not only to avoid the risks and complications associated with general anaesthesia and intubation in patients with right-sided heart failure, but also to prevent the negative consequences of mechanical ventilation, such as ventilator-associated pneumonia, muscular deconditioning and critical care illness. The awake ECMO strategy has proven feasible, even with bridging times of several weeks [38], and has been associated with better outcomes than historical bridging strategies that included intubation and mechanical ventilation $[14,39,40]$.

The use of ECLS in patients who have not been evaluated for transplantation should be avoided unless there is a reasonable perspective for recovery. This may be the case in previously stable patients with a reversible cause of right-sided heart failure (e.g. arrhythmia or infection) or in hitherto untreated or undertreated patients with newly diagnosed PAH. Case reports demonstrating success of this approach are, however, rare $[14,41]$.

TABLE 3 Summary of published data on outcomes of patients with pulmonary arterial hypertension bridged to lung transplant with the use of extracorporeal life support devices

\begin{tabular}{|c|c|c|c|}
\hline First author [ref.] & $\begin{array}{l}\text { Patients who received } \\
\text { ECMO support }\end{array}$ & $\begin{array}{l}\text { Patients bridged } \\
\text { to transplant }\end{array}$ & $\begin{array}{l}\text { Patients discharged } \\
\text { from hospital }\end{array}$ \\
\hline de Perrot [30] & 6 (4 PA-LA, 2 VA ECMO) & $6 / 6(100 \%)$ & $4 / 6(66 \%)$ \\
\hline FUEHNER [39] & 7 (all VA ECMO) & $6 / 7(86 \%)$ & $5 / 6(71 \%)$ \\
\hline Hoopes [73] & 5 (all VA ECMO) & $5 / 5(100 \%)$ & $5 / 5(100 \%)$ \\
\hline LANG [74] & 4 (all VA ECMO) & $4 / 4(100 \%)$ & $4 / 4(100 \%)$ \\
\hline ROSENZWEIG [41] & 6 (all VA ECMO) & $\begin{array}{c}\text { 2/2 }(100 \%) ; 4 \text { received } \\
\text { ECMO as bridge to } \\
\text { recovery }\end{array}$ & $\begin{array}{l}2 / 2(100 \%) ; 1 / 4(25 \%) \\
\text { bridge to recovery patients } \\
\text { survived for }>2 \text { months }\end{array}$ \\
\hline SHAFII [75] & 3 (all VA ECMO) & $2 / 3(66 \%)$ & $2 / 2(100 \%)$ \\
\hline CROTTI $_{\text {[76] }}$ & 4 (3 VA ECMO, 1 VV ECMO) & $4 / 4(100 \%)$ & $3 / 4(75 \%)$ \\
\hline HoETZENECKER [77] & 13 (9 PA-LA, 4 VA ECMO) & $11 / 13(85 \%)$ & $\begin{array}{c}7 / 11(63 \%) \text { survived at } \\
1 \text { year }\end{array}$ \\
\hline SAVALE [56] & 13 (all VA ECMO) & $13 / 13(100 \%)$ & $8 / 13(62 \%)$ \\
\hline DeLLGREn [78] & 2 (both VA ECMO) & $2 / 2(100 \%)$ & $1 / 2(50 \%)$ \\
\hline GLORION [79] & $\begin{array}{c}18 \text { (13 VA ECMO, } 3 \text { VV } \\
\text { ECMO, } 2 \text { PA-LA) }\end{array}$ & $17 / 18(94 \%)$ & $15 / 17(88 \%)$ \\
\hline Total & $\begin{array}{l}81 \text { (66 ECMO, } 15 \text { PA-LA); } \\
77 \text { as bridge to transplant }\end{array}$ & $72 / 77(94 \%)$ & $56 / 72(78 \%)$ \\
\hline
\end{tabular}

ECMO: extracorporeal membrane oxygenation; PA-LA: pulmonary artery to left atrium device; VA: veno-arterial; VV: veno-venous. 
- Established indication: bridge to transplant in patients who have been fully evaluated and accepted for this procedure.

- Potential indications in highly selected cases:

- bridge to transplant decision in potentially eligible patients who have not yet been fully evaluated;

- bridge to recovery in patients with untreated or undertreated $\mathrm{PAH}$, or in patients with a reversible cause of right ventricular failure.

- Contraindication: end-stage disease without a realistic chance for recovery or successful transplantation (futility).

\section{Choice of ECLS}

- Veno-arterial ECMO and the PA-LA approach are currently the only established right ventricular support strategies, but there is rapid evolution in device technologies.

- At present, veno-arterial ECMO is the most widely used ECLS strategy.

- The PA-LA approach should be considered if the expected ECLS time is of longer duration or in children with small femoral arteries.

- The choice of ECLS depends largely on centre experience.

\section{Timing of ECLS}

- All forms of ECLS are associated with potentially life-threatening complications; hence, ECLS should be used only when less invasive treatment options have been exhausted.

- ECLS should be initiated when the clinical course suggests that terminal right heart failure and/or secondary organ failure is imminent despite optimised medical therapy.

- ECLS initiated in patients with advanced PH/PAH undergoing cardiopulmonary resuscitation for right-sided heart failure will rarely result in good outcomes.

\section{ECLS and lung transplantation}

- ECLS is now an established strategy to bridge patients with right heart failure to lung transplantation.

- Centres performing lung transplantation in patients with PAH should have an established ECLS programme.

\section{Lung transplantation}

The modern era of successful lung and heart-lung transplantation started in the early 1980s with patients suffering from $\mathrm{PH}$ [42]. Today, due to the introduction of effective therapies for PAH and chronic thromboembolic $\mathrm{PH}$, lung transplantation is performed less frequently in patients with severe $\mathrm{PH}$, but remains an important treatment option for patients with refractory disease.

\section{When to refer and when to list patients for lung transplantation}

Referral to a transplant centre

General recommendations for the selection of lung transplant candidates have been published elsewhere [37]. In patients with $\mathrm{PAH}$, referral to a lung transplant centre should be considered early, i.e. whenever patients display an inadequate response to treatment and are not at low risk of death despite receiving oral combination therapy (table 4). Early transplant referral is also recommended in patients who are suspected to suffer from disease variants responding poorly to medical therapy, such as pulmonary veno-occlusive disease. An early referral strategy ensures that patients have time to consider lung transplantation with all its consequences, and that centres can fully evaluate potential candidates and optimise their pre-transplant condition. In reality, patients with PAH are often referred in an advanced disease state or when they are rapidly deteriorating, which may prohibit a careful evaluation, thereby exposing them to unnecessary risks and sometimes effectively depriving them of a chance of receiving a donor organ. Early referral for transplant evaluation does not mean that patients are necessarily listed right away; a completed evaluation just allows optimal timing and rapid listing in case of clinical deterioration.

\section{Listing patients for lung transplantation}

Patients suffering from $\mathrm{PAH}$ should be listed for lung transplantation when they present with a high risk of death despite optimised medical therapy, which usually consists of combination therapy including s.c. 
TABLE 4 Specific criteria for lung transplant referral and listing in patients with pulmonary arterial hypertension (PAH)

Referral Potentially eligible patients for whom lung transplantation might be an option in case of treatment failure

ESC/ERS intermediate or high risk or REVEAL risk score $>7$ on appropriate PAH medication

Progressive disease or recent hospitalisation for worsening of PAH

Need for i.v. or s.c. prostacyclin therapy

Known or suspected high-risk variants such as PVOD or PCH, scleroderma, large and progressive pulmonary artery aneurysms

Signs of secondary liver or kidney dysfunction due to PAH or other potentially life-threatening complications such as recurrent haemoptysis

Listing Patient has been fully evaluated and prepared for transplantation

ESC/ERS high risk or REVEAL risk score $>10$ on appropriate PAH medication, usually including i.v. or s.c. prostacyclin analogues

Progressive hypoxaemia, especially in patients with PVOD or PCH

Progressive, but not end-stage, liver or kidney dysfunction due to PAH or life-threatening haemoptysis

ESC: European Society of Cardiology; ERS: European Respiratory Society; REVEAL: Registry to Evaluate Early and Long-term Pulmonary Arterial Hypertension Disease Management; PVOD: pulmonary venoocclusive disease; PCH: pulmonary capillary haemangiomatosis.

or i.v. PCAs (table 4). According to the 2015 European Society of Cardiology (ESC)/European Respiratory Society (ERS) PH guidelines [43, 44], patients are classified as high risk when the estimated 1-year mortality exceeds $10 \%$. Registry data suggest that the 1-year mortality rate of these patients is in fact $>20 \%$ $[45,46]$. Thus, utilising risk stratification tools or scores (i.e. REVEAL (Registry to Evaluate Early and Long-term Pulmonary Arterial Hypertension Disease Management) score $\geqslant 10$ ) [47]) that denote high-risk individuals may be particularly useful in deciding when to refer a patient for evaluation. Since the 1-year mortality after lung transplantation for severe $\mathrm{PH}$ in experienced centres is currently around $10 \%[48,49]$, a survival benefit can be expected for such patients.

Patients listed for lung transplantation benefit from pre-transplant rehabilitation programmes [50].

With the introduction of the lung allocation score (LAS), waiting list mortality has decreased and the odds of receiving a donor organ have increased for most major lung diseases, including PAH [51, 52]. Still, the LAS does not always adequately reflect disease severity in patients suffering from PAH [53]. In a multivariable analysis comparing mortality predicted by the LAS system to actual mortality in REVEAL, two additional variables were independently associated with increased mortality compared with the LAS: mean right atrial pressure $\geqslant 14 \mathrm{mmHg}$ and 6-min walk distance $\leqslant 300 \mathrm{~m}$ [54]. These two factors, in addition to total bilirubin and cardiac index, were added to a modified LAS, released in February 2015 [55], which also reweighted weight, list urgency and post-transplant outcomes in favour of PAH. The effect of these changes on outcome should be forthcoming in the next several years.

In some countries, an "exceptional LAS" can be obtained for patients with severe PH [56]. Some other countries not using the LAS have successfully implemented high-priority programmes for these patients [57].

\section{Transplant procedure, post-transplant care and outcomes}

Major progress has been made over the past years in lung transplantation for PAH. One of the most important innovations was the use of ECMO support during and after transplantation [58]. Meanwhile, the intra-operative use of ECMO has almost completely replaced the use of conventional cardiopulmonary bypass as it has been associated with a reduction of peri-operative complications including renal failure, a reduced need for transfusions of blood products and (in some, but not all, series) with better survival [49, 59-63]. In patients with $\mathrm{PH}$ and right-sided heart failure undergoing transplantation, veno-arterial ECMO is occasionally established prior to general anaesthesia to avoid haemodynamic instability.

A better understanding of the pathophysiological changes after transplantation for $\mathrm{PH}$ with adaptation of therapeutic strategies (e.g. achieving a negative fluid balance including use of haemofiltration when necessary and extended ECMO support) has substantially reduced the occurrence of early graft dysfunction, which was the major obstacle of post-transplant survival in these patients and the main reason why the early post-operative mortality was historically higher in patients undergoing lung transplantation for PAH than for most other end-stage lung diseases [64]. 
As already reported in 1999 [65], the main cause of primary graft dysfunction in these patients was not residual $\mathrm{PH}$, but left ventricular failure [33]. However, the notion that the small and "unconditioned" left ventricles of patients with severe $\mathrm{PH}$ are prone to developing diastolic dysfunction when exposed to a normal or high pre-load after transplantation only recently came into a wider focus of interest [32, 33, 48]. Left ventricular dysfunction results in elevated left-sided filling pressures and pulmonary oedema, which tends to worsen whenever patients are awake and agitated. In the past, this has frequently led to a vicious cycle making it difficult, and sometimes impossible, to wean patients from the ventilator, thereby exposing them to the risks associated with prolonged mechanical ventilation and intensive care. To overcome this problem, several centres over many years have used combined heart and lung transplantation for patients with severe PH $[66,67]$. Today, however, the post-operative prolongation of veno-arterial ECMO after transplantation effectively prevents primary graft dysfunction [48, 68]. Two different approaches have been described: 1) prolongation of ECMO with extubation first and continuation of ECMO support for 3-7 days [48] or 2) brief post-operative prolongation of ECMO in intubated patients until stabilisation of haemodynamics and normalisation of fluid balance followed by a few days of ventilation [49]. For both strategies, 1-year survival rates $>90 \%$ have been reported $[48,49]$. There is now consensus among experts that bilateral lung transplantation is the procedure of choice for most patients with $\mathrm{PAH}$. Of note, almost any right ventricle recovers within a few weeks after transplantation, regardless of the degree of pre-transplant dilatation and dysfunction, and regardless of the severity of pre-operative tricuspid regurgitation [69-71].

\section{Recommendations for lung transplantation in patients with PH/PAH}

- Repeated risk assessment is pivotal to identify the appropriate time for initiating transplant evaluation.

- Established and validated risk prediction tools such as the REVEAL risk score or the ESC/ERS risk prediction strategy should be applied in patients with $\mathrm{PAH}$ to determine timing for referral to a transplant centre.

- Potentially eligible candidates should be referred for lung transplantation evaluation early, i.e. when they have an inadequate response to oral combination therapy, indicated by an intermediate or high risk according to the ESC/ERS risk stratification strategy or by a REVEAL risk score $>7$.

- Listing for lung transplantation should be considered in patients who present with a high risk of death according to the ESC/ERS risk stratification strategy or by a REVEAL risk score $\geqslant 10$ despite receiving optimised medical therapy including s.c. or i.v. PCAs, as the expected mortality on medical therapy exceeds the expected mortality after bilateral lung transplantation. Depending on local circumstances, listing of patients at intermediate risk might be appropriate in some countries.

- Timing of listing must depend on expected local waiting time.

- Bilateral lung transplantation is the method of choice in patients with PH.

- There is no degree of right ventricular dysfunction that precludes bilateral lung transplantation in patients with PAH.

- Despite advances in ICU management and ECLS, the ideal recipient is an ambulant outpatient.

- Extended use of ECMO support should be considered after lung transplantation in patients with $\mathrm{PH}$ to prevent early graft dysfunction.

- Given the low number and high risk of lung transplants performed for PAH worldwide, this procedure should be concentrated in specialised centres.

\section{Ethical considerations}

Despite therapeutic progress, $\mathrm{PAH}$ remains a chronic, incurable and often fatal disease. Advanced ICU treatment including the use of ECLS is warranted whenever there is a clear treatment objective, be it recovery or transplantation. However, if these treatment goals are not realistically achievable, advanced intensive care will be futile and should be replaced by best supportive care, as should be the case in all patients who have reached the end of their life. It is important to consider the patient's preferences whenever possible and to proactively discuss end-of-life matters early on. Still, patients may change their perspectives once they are no longer in a stable situation but face imminent death.

\section{Future perspectives}

In the foreseeable future, PAH will remain an incurable, chronic and progressive disease. Reverse remodelling of the pulmonary vasculopathy is a main target of ongoing research, but success in human disease has been limited so far [72]. Hence, future studies should aim at developing new drugs to affect the disease itself, but also at developing new means to support the failing right ventricle. The development of (awake) ECMO as a bridge to transplantation has been a first step. Future devices will allow an extended use of extracorporeal or intracorporeal support systems, even in outpatients, like the use of left ventricular assist devices in patients with left-sided heart failure. It is impossible to foresee if or when such devices 
may obviate the need for lung transplantation. For the time being, lung transplantation remains an important treatment option for patients with otherwise refractory $\mathrm{PAH}$.

Conflict of interest: M.M. Hoeper reports personal fees for speaking/consulting from Actelion, Bayer, GSK and Merck. R.L. Benza has nothing to disclose. P. Corris reports grants and personal fees for lectures and consultations from Actelion and Bayer, and personal fees for lectures and consultations from MSD, during the conduct of the study. M. de Perrot reports grants and personal fees for lectures and consultations from Bayer, Merck and Actelion, during the conduct of the study. E. Fadel has nothing to disclose. A.M. Keogh reports personal fees for lectures and consultations from Bayer, Actelion, GSK and Pfizer, during the conduct of the study. C. Kühn reports personal fees for lecturing from Maquet and Zoll, during the conduct of the study. L. Savale reports grants and personal fees for lectures and consultations from Bayer and Actelion, and personal fees for lectures and consultations from GSK and MSD, during the conduct of the study. W. Klepetko has nothing to disclose.

\section{References}

1 Price LC, Wort SJ, Finney SJ, et al. Pulmonary vascular and right ventricular dysfunction in adult critical care: current and emerging options for management: a systematic literature review. Crit Care 2010; 14: R169.

2 Hoeper MM, Granton J. Intensive care unit management of patients with severe pulmonary hypertension and right heart failure. Am J Respir Crit Care Med 2011; 184: 1114-1124.

3 Harjola VP, Mebazaa A, Celutkiene J, et al. Contemporary management of acute right ventricular failure: a statement from the Heart Failure Association and the Working Group on Pulmonary Circulation and Right Ventricular Function of the European Society of Cardiology. Eur J Heart Fail 2016; 18: 226-241.

4 Niebauer J, Volk HD, Kemp M, et al. Endotoxin and immune activation in chronic heart failure: a prospective cohort study. Lancet 1999; 353: 1838-1842.

5 Seeto RK, Fenn B, Rockey DC. Ischemic hepatitis: clinical presentation and pathogenesis. Am J Med 2000; 109: $109-113$.

6 Dai DF, Swanson PE, Krieger EV, et al. Congestive hepatic fibrosis score: a novel histologic assessment of clinical severity. Mod Pathol 2014; 27: 1552-1558.

7 Myers RP, Cerini R, Sayegh R, et al. Cardiac hepatopathy: clinical, hemodynamic, and histologic characteristics and correlations. Hepatology 2003; 37: 393-400.

8 Megalla S, Holtzman D, Aronow WS, et al. Predictors of cardiac hepatopathy in patients with right heart failure. Med Sci Monit 2011; 17: Cr537-Cr541.

9 Mullens W, Abrahams Z, Francis GS, et al. Importance of venous congestion for worsening of renal function in advanced decompensated heart failure. J Am Coll Cardiol 2009; 53: 589-596.

10 Ranchoux B, Bigorgne A, Hautefort A, et al. Gut-lung connection in pulmonary arterial hypertension. Am J Respir Cell Mol Biol 2017; 56: 402-405.

11 Krack A, Sharma R, Figulla HR, et al. The importance of the gastrointestinal system in the pathogenesis of heart failure. Eur Heart J 2005; 26: 2368-2374.

12 Sztrymf B, Souza R, Bertoletti L, et al. Prognostic factors of acute heart failure in patients with pulmonary arterial hypertension. Eur Respir J 2010; 35: 1286-1293.

13 Walley KR. Use of central venous oxygen saturation to guide therapy. Am J Respir Crit Care Med 2011; 184: 514-520.

14 Javidfar J, Brodie D, Iribarne A, et al. Extracorporeal membrane oxygenation as a bridge to lung transplantation and recovery. J Thorac Cardiovasc Surg 2012; 144: 716-721.

15 Olsson KM, Nickel NP, Tongers J, et al. Atrial flutter and fibrillation in patients with pulmonary hypertension. Int J Cardiol 2013; 167: 2300-2305.

16 Held M, Walthelm J, Baron S, et al. Functional impact of pulmonary hypertension due to hypoventilation and changes under noninvasive ventilation. Eur Respir J 2014; 43: 156-165.

17 Olsson KM, Frank A, Fuge J, et al. Acute hemodynamic effects of adaptive servoventilation in patients with pre-capillary and post-capillary pulmonary hypertension. Respir Res 2015; 16: 137.

18 Ghignone M, Girling L, Prewitt RM. Volume expansion versus norepinephrine in treatment of a low cardiac output complicating an acute increase in right ventricular afterload in dogs. Anesthesiology 1984; 60: 132-135.

19 Delcroix M, Naeije R. Optimising the management of pulmonary arterial hypertension patients: emergency treatments. Eur Respir Rev 2010; 19: 204-211.

20 Sitbon $\mathrm{O}$, Jais $\mathrm{X}$, Savale L, et al. Upfront triple combination therapy in pulmonary arterial hypertension: a pilot study. Eur Respir J 2014; 43: 1691-1697.

21 Kerbaul F, Rondelet B, Demester JP, et al. Effects of levosimendan versus dobutamine on pressure load-induced right ventricular failure. Crit Care Med 2006; 34: 2814-2819.

22 Kerbaul F, Gariboldi V, Giorgi R, et al. Effects of levosimendan on acute pulmonary embolism-induced right ventricular failure. Crit Care Med 2007; 35: 1948-1954.

23 Sarkar J, Golden PJ, Kajiura LN, et al. Vasopressin decreases pulmonary-to-systemic vascular resistance ratio in a porcine model of severe hemorrhagic shock. Shock 2015; 43: 475-482.

24 Scheurer MA, Bradley SM, Atz AM. Vasopressin to attenuate pulmonary hypertension and improve systemic blood pressure after correction of obstructed total anomalous pulmonary venous return.J Thorac Cardiovasc Surg 2005; 129: 464-466.

25 Machuca TN, de Perrot M. Mechanical support for the failing right ventricle in patients with precapillary pulmonary hypertension. Circulation 2015; 132: 526-536.

26 Rajagopal K, Hoeper MM. State of the art: bridging to lung transplantation using artificial organ support technologies. J Heart Lung Transplant 2016; 35: 1385-1398.

27 Verbelen T, Claus $\mathrm{P}$, Burkhoff $\mathrm{D}$, et al. Low-flow support of the chronic pressure-overloaded right ventricle induces reversed remodeling. J Heart Lung Transplant 2018; 37: 151-160.

28 Hoeper MM, Tudorache I, Kuhn C, et al. Extracorporeal membrane oxygenation watershed. Circulation 2014; 130: $864-865$. 
29 Strueber M, Hoeper MM, Fischer S, et al. Bridge to thoracic organ transplantation in patients with pulmonary arterial hypertension using a pumpless lung assist device. Am J Transplant 2009; 9: 853-857.

30 de Perrot M, Granton JT, McRae K, et al. Impact of extracorporeal life support on outcome in patients with idiopathic pulmonary arterial hypertension awaiting lung transplantation. J Heart Lung Transplant 2011; 30: 997-1002.

31 Rosenzweig EB, Chicotka S, Bacchetta M. Right ventricular assist device use in ventricular failure due to pulmonary arterial hypertension: lessons learned. J Heart Lung Transplant 2016; 35: 1272-1274.

32 Knight DS, Steeden JA, Moledina S, et al. Left ventricular diastolic dysfunction in pulmonary hypertension predicts functional capacity and clinical worsening: a tissue phase mapping study. J Cardiovasc Magn Reson 2015; 17: 116.

33 Avriel A, Klement AH, Johnson SR, et al. Impact of left ventricular diastolic dysfunction on lung transplantation outcome in patients with pulmonary arterial hypertension. Am J Transplant 2017; 17: 2705-2711.

34 Punnoose L, Burkhoff D, Rich S, et al. Right ventricular assist device in end-stage pulmonary arterial hypertension: insights from a computational model of the cardiovascular system. Prog Cardiovasc Dis 2012; 55: 234-243.

35 Schmitto JD, Burkhoff D, Avsar M, et al. Two axial-flow synergy micro-pumps as a biventricular assist device in an ovine animal model. J Heart Lung Transplant 2012; 31: 1223-1229.

36 Hayanga AJ, Aboagye J, Esper S, et al. Extracorporeal membrane oxygenation as a bridge to lung transplantation in the United States: an evolving strategy in the management of rapidly advancing pulmonary disease. $J$ Thorac Cardiovasc Surg 2015; 149: 291-296.

37 Weill D, Benden C, Corris PA, et al. A consensus document for the selection of lung transplant candidates: 2014 - an update from the Pulmonary Transplantation Council of the International Society for Heart and Lung Transplantation. J Heart Lung Transplant 2015; 34: 1-15.

38 Olsson KM, Simon A, Strueber M, et al. Extracorporeal membrane oxygenation in nonintubated patients as bridge to lung transplantation. Am J Transplant 2010; 10: 2173-2178.

39 Fuehner T, Kuehn C, Hadem J, et al. Extracorporeal membrane oxygenation in awake patients as bridge to lung transplantation. Am J Respir Crit Care Med 2012; 185: 763-768.

40 Lang G, Kim D, Aigner C, et al. Awake extracorporeal membrane oxygenation bridging for pulmonary retransplantation provides comparable results to elective retransplantation. J Heart Lung Transplant 2014; 33: $1264-1272$.

41 Rosenzweig EB, Brodie D, Abrams DC, et al. Extracorporeal membrane oxygenation as a novel bridging strategy for acute right heart failure in group 1 pulmonary arterial hypertension. ASAIO J 2014; 60: 129-133.

42 Reitz BA, Wallwork JL, Hunt SA, et al. Heart-lung transplantation: successful therapy for patients with pulmonary vascular disease. N Engl J Med 1982; 306: 557-564.

43 Galiè N, Humbert M, Vachiery JL, et al. 2015 ESC/ERS Guidelines for the diagnosis and treatment of pulmonary hypertension. Eur Heart J 2016; 37: 67-119.

44 Galiè N, Humbert M, Vachiery JL, et al. 2015 ESC/ERS Guidelines for the diagnosis and treatment of pulmonary hypertension. Eur Respir J 2015; 46: 903-975.

45 Kylhammar D, Kjellstrom B, Hjalmarsson C, et al. A comprehensive risk stratification at early follow-up determines prognosis in pulmonary arterial hypertension. Eur Heart J 2018; 39: 4175-4181.

46 Hoeper MM, Kramer T, Pan Z, et al. Mortality in pulmonary arterial hypertension: prediction by the 2015 European pulmonary hypertension guidelines risk stratification model. Eur Respir J 2017; 50: 1700740.

47 Benza RL, Gomberg-Maitland M, Miller DP, et al. The REVEAL Registry risk score calculator in patients newly diagnosed with pulmonary arterial hypertension. Chest 2012; 141: 354-362.

48 Tudorache I, Sommer W, Kuhn C, et al. Lung transplantation for severe pulmonary hypertension - awake extracorporeal membrane oxygenation for postoperative left ventricular remodelling. Transplantation 2015; 99: 451-458.

49 Moser B, Jaksch P, Taghavi S, et al. Lung transplantation for idiopathic pulmonary arterial hypertension on intraoperative and postoperatively prolonged extracorporeal membrane oxygenation provides optimally controlled reperfusion and excellent outcome. Eur J Cardiothorac Surg 2018; 53: 178-185.

50 Wickerson L, Rozenberg D, Janaudis-Ferreira T, et al. Physical rehabilitation for lung transplant candidates and recipients: an evidence-informed clinical approach. World J Transplant 2016; 6: 517-531.

51 Schaffer JM, Singh SK, Joyce DL, et al. Transplantation for idiopathic pulmonary arterial hypertension: improvement in the lung allocation score era. Circulation 2013; 127: 2503-2513.

52 Egan TM, Edwards LB. Effect of the lung allocation score on lung transplantation in the United States. $J$ Heart Lung Transplant 2016; 35: 433-439.

53 Chen H, Shiboski SC, Golden JA, et al. Impact of the lung allocation score on lung transplantation for pulmonary arterial hypertension. Am J Respir Crit Care Med 2009; 180: 468-474.

54 Benza RL, Miller DP, Frost A, et al. Analysis of the lung allocation score estimation of risk of death in patients with pulmonary arterial hypertension using data from the REVEAL Registry. Transplantation 2010; 90: 298-305.

55 Organ Procurement and Transplantation Network. Changes to the lung allocation system. 2015. https://optn. transplant.hrsa.gov/news/changes-to-the-lung-allocation-system/ Date last accessed: November 21, 2018.

56 Gottlieb J, Smits J, Schramm R, et al. Lung transplantation in Germany since the introduction of the lung allocation score. Dtsch Arztebl Int 2017; 114: 179-185.

57 Savale L, Le Pavec J, Mercier O, et al. Impact of high-priority allocation on lung and heart-lung transplantation for pulmonary hypertension. Ann Thorac Surg 2017; 104: 404-411.

58 Pereszlenyi A, Lang G, Steltzer $\mathrm{H}$, et al. Bilateral lung transplantation with intra- and postoperatively prolonged ECMO support in patients with pulmonary hypertension. Eur J Cardiothorac Surg 2002; 21: 858-863.

59 Ius F, Kuehn C, Tudorache I, et al. Lung transplantation on cardiopulmonary support: venoarterial extracorporeal membrane oxygenation outperformed cardiopulmonary bypass. J Thorac Cardiovasc Surg 2012; 144: 1510-1516.

60 Biscotti M, Yang J, Sonett J, et al. Comparison of extracorporeal membrane oxygenation versus cardiopulmonary bypass for lung transplantation. J Thorac Cardiovasc Surg 2014; 148: 2410-2416.

61 Bermudez CA, Shiose A, Esper SA, et al. Outcomes of intraoperative venoarterial extracorporeal membrane oxygenation versus cardiopulmonary bypass during lung transplantation. Ann Thorac Surg 2014; 98: 1936-1943. 
62 Machuca TN, Collaud S, Mercier O, et al. Outcomes of intraoperative extracorporeal membrane oxygenation versus cardiopulmonary bypass for lung transplantation. J Thorac Cardiovasc Surg 2015; 149: 1152-1157.

63 Hoetzenecker K, Schwarz S, Muckenhuber M, et al. Intraoperative extracorporeal membrane oxygenation and the possibility of postoperative prolongation improve survival in bilateral lung transplantation. $J$ Thorac Cardiovasc Surg 2018; 155: 2193-2206.

64 Christie JD, Edwards LB, Kucheryavaya AY, et al. The Registry of the International Society for Heart and Lung Transplantation: twenty-seventh official adult lung and heart-lung transplant report - 2010. J Heart Lung Transplant 2010; 29: 1104-1118.

65 Birsan T, Kranz A, Mares P, et al. Transient left ventricular failure following bilateral lung transplantation for pulmonary hypertension. J Heart Lung Transplant 1999; 18: 304-309.

66 Franke U, Wiebe K, Harringer W, et al. Ten years experience with lung and heart-lung transplantation in primary and secondary pulmonary hypertension. Eur J Cardiothorac Surg 2000; 18: 447-452.

67 Fadel E, Mercier O, Mussot S, et al. Long-term outcome of double-lung and heart-lung transplantation for pulmonary hypertension: a comparative retrospective study of 219 patients. Eur J Cardiothorac Surg 2010; 38: $277-284$

68 Kortchinsky T, Mussot S, Rezaiguia S, et al. Extracorporeal life support in lung and heart-lung transplantation for pulmonary hypertension in adults. Clin Transplant 2016; 30: 1152-1158.

69 Gorter TM, Verschuuren EAM, van Veldhuisen DJ, et al. Right ventricular recovery after bilateral lung transplantation for pulmonary arterial hypertension. Interact Cardiovasc Thorac Surg 2017; 24: 890-897.

70 Kasimir MT, Seebacher G, Jaksch P, et al. Reverse cardiac remodelling in patients with primary pulmonary hypertension after isolated lung transplantation. Eur J Cardiothorac Surg 2004; 26: 776-781.

71 Sarashina T, Nakamura K, Akagi S, et al. Reverse right ventricular remodeling after lung transplantation in patients with pulmonary arterial hypertension under combination therapy of targeted medical drugs. Circ J 2017; 81: 383-390.

72 Pullamsetti SS, Schermuly R, Ghofrani A, et al. Novel and emerging therapies for pulmonary hypertension. Am J Respir Crit Care Med 2014; 189: 394-400.

73 Hoopes CW, Kukreja J, Golden J, et al. Extracorporeal membrane oxygenation as a bridge to pulmonary transplantation. J Thorac Cardiovasc Surg 2013; 145: 862-867.

74 Lang G, Taghavi S, Aigner C, et al. Primary lung transplantation after bridge with extracorporeal membrane oxygenation: a plea for a shift in our paradigms for indications. Transplantation 2012; 93: 729-736.

75 Shafii AE, Mason DP, Brown CR, et al. Growing experience with extracorporeal membrane oxygenation as a bridge to lung transplantation. ASAIO J 2012; 58: 526-529.

76 Crotti S, Iotti GA, Lissoni A, et al. Organ allocation waiting time during extracorporeal bridge to lung transplant affects outcomes. Chest 2013; 144: 1018-1025.

77 Hoetzenecker K, Donahoe L, Yeung JC, et al. Extracorporeal life support as a bridge to lung transplantation experience of a high-volume transplant center. J Thorac Cardiovasc Surg 2018; 155: 1316-1328.

78 Dellgren G, Riise GC, Sward K, et al. Extracorporeal membrane oxygenation as a bridge to lung transplantation: a long-term study. Eur J Cardiothorac Surg 2015; 47: 95-100.

79 Glorion M, Mercier O, Mitilian D, et al. Central versus peripheral cannulation of extracorporeal membrane oxygenation support during double lung transplant for pulmonary hypertension. Eur J Cardiothorac Surg 2018; 54: 341-347.

80 Olsson KM, Halank M, Egenlauf B, et al. Decompensated right heart failure, intensive care and perioperative management in patients with pulmonary hypertension: updated recommendations from the Cologne Consensus Conference 2018. Int J Cardiol 2018; 272S: 46-52. 